\title{
A Case of Thoracic Disc Herniation Extruded to the Dorsal Epidural Space
}

\author{
Shigeta Takeuchi', Yuichirou Yokoyama1, Yasuaki Iida1, Keiji Hasegawa1, Akihito Wada1, \\ Ryoichi Fukano', Kazutoshi Shibiuya', Hiroshi Takahashi1 \\ ${ }^{1}$ Department of Orthopaedic Surgery, Toho University School of Medicine, Tokyo, Japan \\ ${ }^{2}$ Department of Pathology, Toho University School of Medicine, Tokyo, Japan \\ Email: drkan@med.toho-u.ac.jp
}

Received 6 July 2015; accepted 2 August 2015; published 5 August 2015

Copyright @ 2015 by authors and Scientific Research Publishing Inc.

This work is licensed under the Creative Commons Attribution International License (CC BY).

http://creativecommons.org/licenses/by/4.0/

(c) (i) Open Access

\begin{abstract}
We encountered a patient with thoracic disc herniation that extruded to the dorsal epidural space. The patient was a 78-year-old man in whom listlessness of the lower limbs developed without an inducer and walking became difficult. The patient was diagnosed as having a thoracic spinal cord tumor on MRI by a physician, and was referred to our hospital. Since ring enhancement was observed on contrast MRI performed at our hospital, the patient was diagnosed with disc herniation and surgery was performed. A hernia continuous with the intervertebral space that extruded to the dorsal epidural space was excised. At the final follow up, 1 year and 4 months after surgery, the patient could walk with a cane. Among thoracic disc herniation cases, hernia extruded to the dorsal epidural space is rare and difficult to diagnose by imaging before surgery, but evaluation using contrast MRI is useful in the diagnosis. When a space-occupying lesion is observed in the spinal canal in the lower thoracic spinal region, it is necessary to evaluate it by contrast MRI in consideration of thoracic disc herniation.
\end{abstract}

\section{Keywords}

Disc Hernia, Dorsal Epidural Space, Thoracic Spine

\section{Introduction}

In general, thoracic disc herniation is rare compared with cervical and lumbar disc herniation; accounting for $0.5 \%$ - 4\% of all disc herniation cases [1] [2]. The frequent site of development is in the lower thoracic vertebrae, mainly Th9/10-Th12/L1, and Arce et al. reported that it developed in this region in 176 (68\%) of 258 patients [3]. Thoracic disc herniation that has extruded to the dorsal epidural space is very rare.

How to cite this paper: Takeuchi, S., Yokoyama, Y., lida, Y., Hasegawa, K., Wada, A., Fukano, R., Shibiuya, K. and Takahashi, H. (2015) A Case of Thoracic Disc Herniation Extruded to the Dorsal Epidural Space. Open Journal of Orthopedics, 5, 229-234. http://dx.doi.org/10.4236/ojo.2015.58030 
We encountered a patient with thoracic disc herniation that extruded to the dorsal epidural space.

\section{Case Report}

The patient was a 78-year-old male who presented with the chief complaint of pain and listlessness of the bilateral lower limbs. Pain had manifested in the bilateral lower limbs without an inducer 2 months earlier, followed by listlessness of the bilateral lower limbs one week prior to presentation. Walking became difficult, and the patient visited a physician. A space-occupying lesion was noted in the spinal canal at the Th11/12 level on MRI. Thoracic spinal cord tumor was suspected and the patient was referred to our hospital.

His past medical history included hypertension, old myocardial infarction, and prostatic hyperplasia.

The muscular strength had decreased in the bilateral lower limbs. It was grade MMT2 in the iliopsoas, quadriceps, and anterior tibial muscles, MMT3 in the extensor and flexor hallucis longus muscles, and walking was difficult. Hypesthesia of warmth and pain was noted the inguinal region, and senses of position and vibration had been lost. The patellar and Achilles tendon reflexes were enhanced, and the Babinski reflex was observed. Moreover, bladder and rectal disturbances were noted.

No abnormal findings were detected in blood chemistry.

On plain thoracic vertebral radiography, narrowing of the intervertebral space height was noted at Th8/9, 9/10, and 11/12, and ossification of the anterior longitudinal ligament (OALL) was observed at the Th8/9, 9/10, 10/11, and $11 / 12$ intervertebral regions.

On plain CT, ossification of the yellow ligament (OYL) was noted on the right side at the Th11/12 level. On thoracic vertebral MRI, an epidural lesion exhibiting iso-intensity on T1- and T2-weighted imaging and an enhanced margin on Gd contrast imaging were evident on the dorsal side of the left dura mater at the Th11/12 level (Figure 1).

While the diagnosis made by the previous physician was spinal cord tumor, we diagnosed it as thoracic disc herniation that had extruded to the dorsal epidural space, based on the characteristic contrast MR findings, and

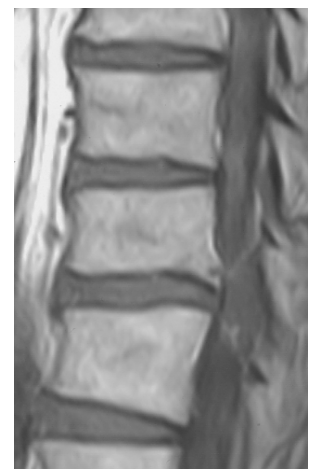

(a)

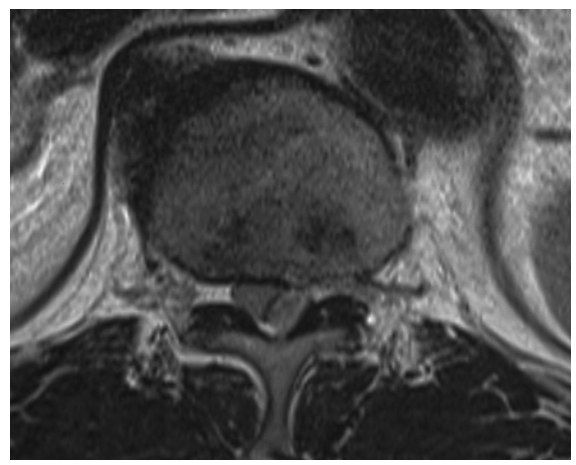

(c)

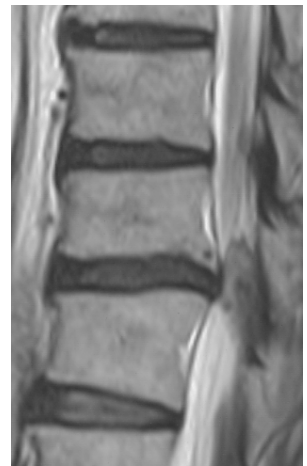

(b)

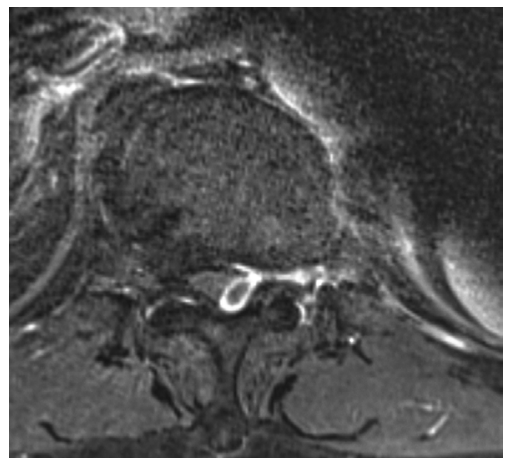

(d)

Figure 1. Thoracic spine MRI on admission. A space-occupying lesion showing iso-intensity on T1- and T2-weighted imaging and an enhanced margin on Gd-contrast imaging was evident in the spinal canal on the left dorsal dura side at the Th11/12 level. (a) Sagittal T1WI; (b) Sagittal T2WI; (c) Axial T2WI; (d) Axial Gd-DTPA. 
performed emergency surgery.

For surgery, posterior decompression fixation was planned. During surgery, the hernia mass was present on the left dorsal side of the dura mater at the Th11/12 level and excluded the dura mater on the left dorsal side. The hernia mass was partially adherent to the dura mater and continuous to the Th11/12 intervertebral disc. After excision, bulging of the dural canal became favorable, and posterior fixation was applied using local bone (Figure 2).

Pathological evaluation of the excised specimen showed degenerated intervertebral disc tissue with partial microvascular outgrowth was observed (Figure 3).

Postoperatively the bilateral lower limb pain remitted immediately. The patient became able to kneel the day following surgery, and was able to walk while holding parallel bars 3 weeks after surgery. Dysuria improved 4.5 weeks after surgery.

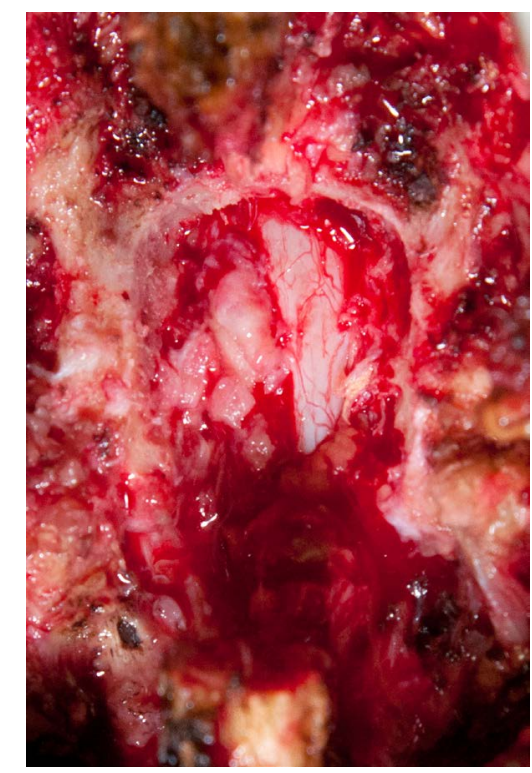

(a)

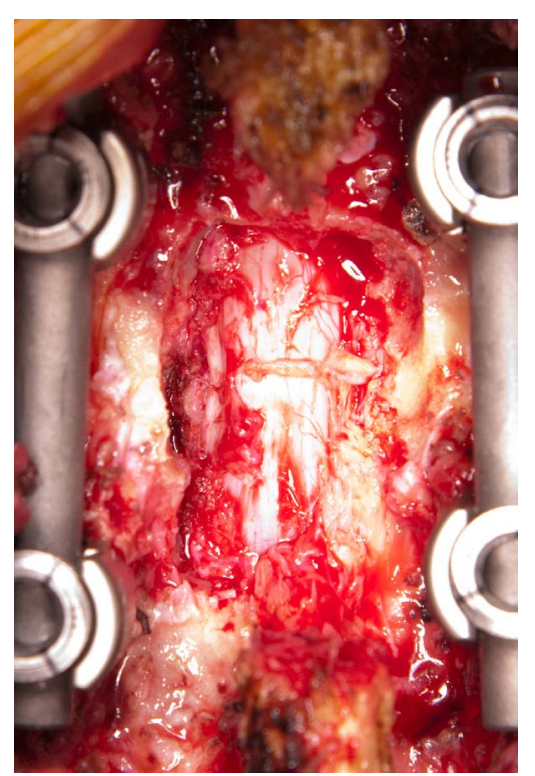

(b)

Figure 2. Intraoperative findings. (a) A hernia mass was present on the dorsal side of the left dura sac and the dural sac was excluded; (b) After excision, bulging of the dura sac was improved. 


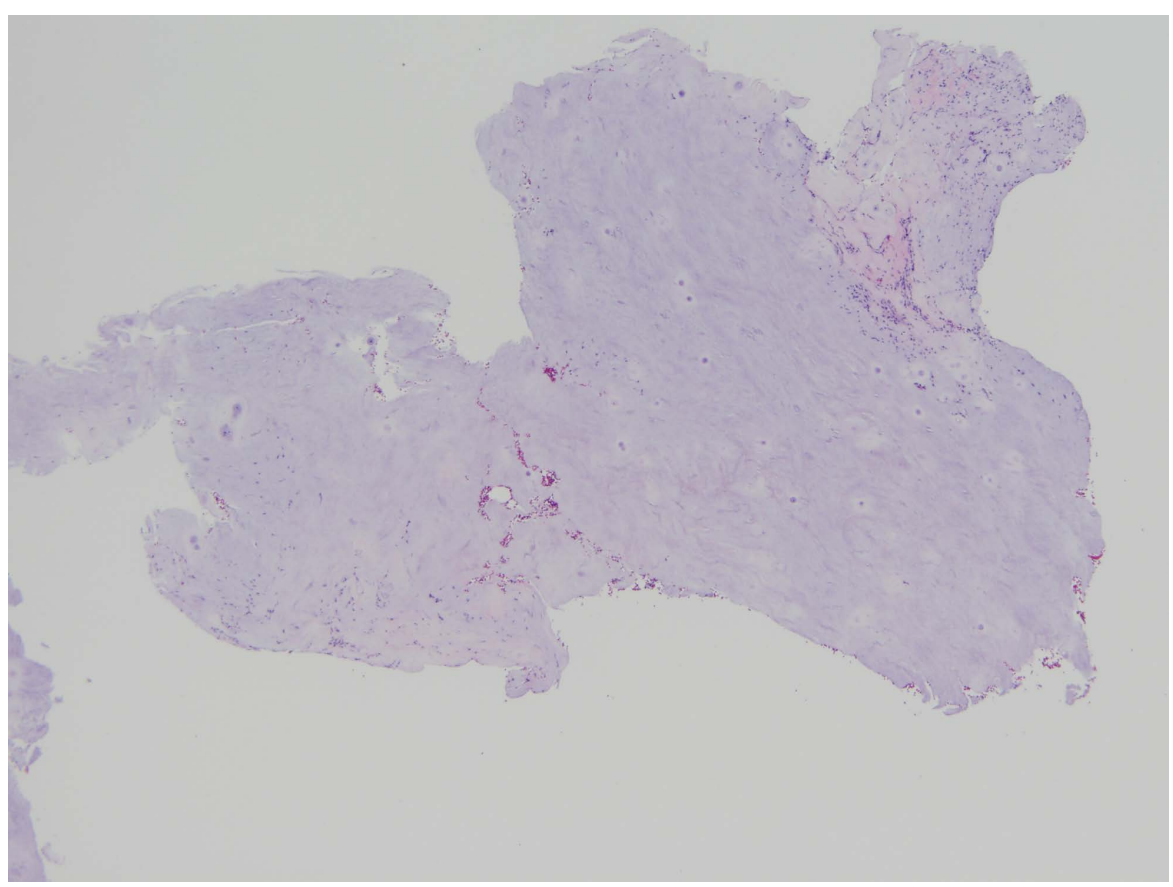

(a)

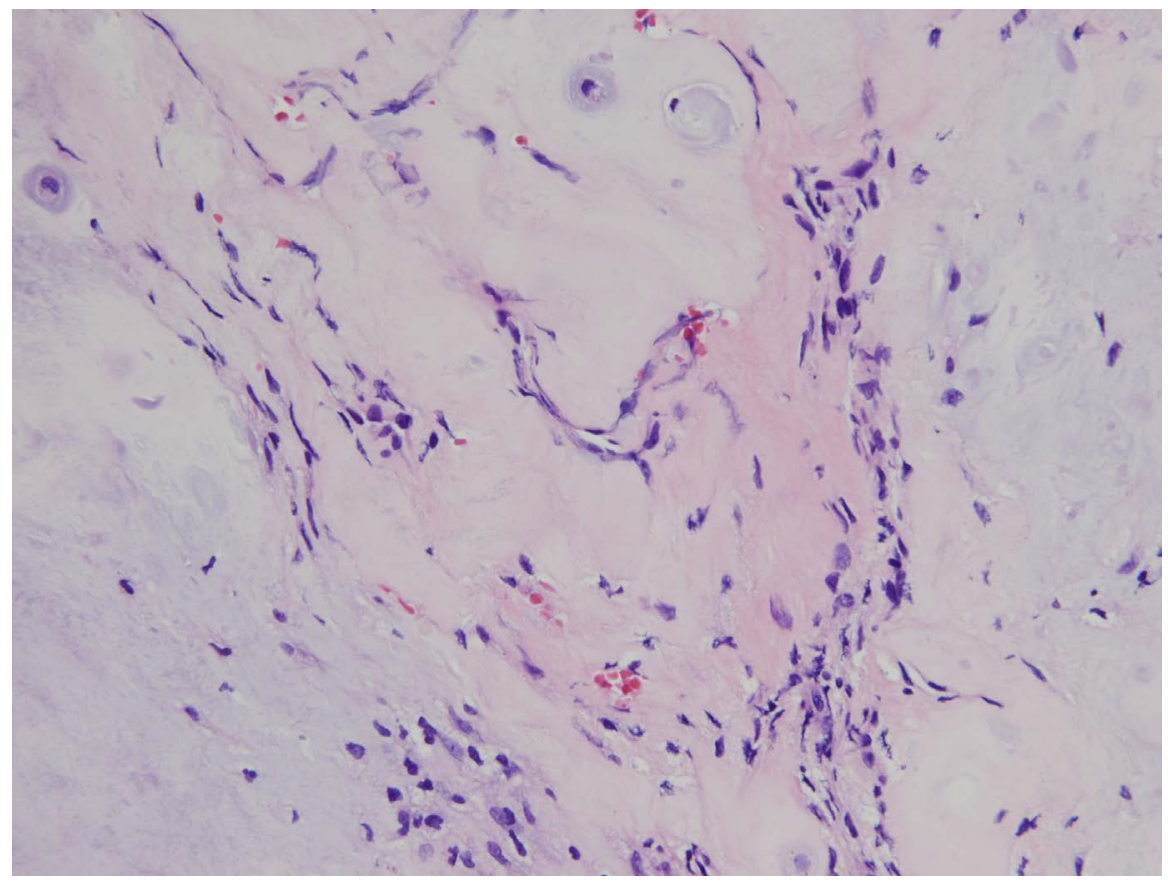

(b)

Figure 3. Pathology. The intervertebral disc tissue was degenerated, and microvascular outgrowth was noted in some parts. (a) HE staining, $\times 4$; (b) HE staining, $\times 100$.

On the final follow up 1 year and 4 months after surgery, the patient was able to walk with a cane. Senses of proprioception and vibration remained only below the knee joint on the right side and in the foot on the left side.

\section{Discussion}

In general, thoracic disc herniation is rare compared with cervical and lumbar disc herniation; accounting for 0.5\% 
- 4\% of all disc herniation cases [1] [2]. The frequent site of development is in the lower thoracic vertebrae, mainly Th9/10-Th12/L1, and Arce et al. reported that it developed in this region in 176 (68\%) of 258 patients [3].

To our knowledge, only 13 cases of thoracic disc herniation, including our patient and 4 cases of thoracic disc herniation that have extruded to the dorsal epidural space have been reported in Japan [4]-[14] and other countries [15]-[18], respectively, showing that it is very rare.

The clinical symptoms of thoracic disc herniation are not specific, and diverse symptoms can develop, such as motor paralysis of the lower limbs, sensory disturbance in regions that are innervated from below the impaired region, and bladder and rectal disturbance [4]-[18].

Spinal cord symptoms gradually progress in many patients. In our patient, bilateral lower limb pain developed without an inducer, i.e., trauma, and listlessness of the bilateral lower limbs developed 2 months later.

Regarding the preoperative diagnosis, dorsally extruding free hernia has been diagnosed before surgery in only 9 (52\%) of 17 reported cases, due to the presence of spinal cord tumor, ossification of the posterior longitudinal ligament, OYL, and epidural hematoma, and some cases were difficult to diagnose [4]-[18].

MRI is important in making a definite diagnosis, and confirmation of the presence or absence of ring enhancement and continuity to the intervertebral disc by contrast MRI is particularly important [4]-[6] [8] [9] [12] [14]-[18].

No consensus has been reached with respect to the developmental mechanism of thoracic disc herniation that has extruded to the dorsal epidural space.

We considered the mechanism of development in our patient as follows:

Elevated intrathoracic pressure has been considered as a functional factor. Yano et al. [19] reported a case of a patient with thoracic disc herniation that developed as sudden complete paraplegia upon defecation. They discussed a Valsalva-like maneuver, i.e., Valsalva-like maneuver may elevate the intrathoracic pressure due to defecation, exercise, and hypertension, leading to protusion of the intervertebral disc. This possibility cannot be ruled for our patient as he had a past medical history of hypertension.

Mobility of the lower thoracic spine in the anteroposterior and side flexion is virtually equivalent to that of the upper lumbar spine [20], suggesting involvement of a dynamic element.

As an anatomical factor, the spinal canal morphology in the lower thoracic spine is similar to that of the upper lumbar spine; the region that has a high incidence of herniation extruding to the dorsal epidural space.

In addition, OYL was noted on the right side in our patient, suggesting that the hernia was extruded to the dorsal epidural space on the left side because it could easily pass through.

\section{Conclusion}

We encountered a patient with thoracic disc herniation that extruded to the dorsal epidural space, which is rare. Spinal cord tumor, hematoma, cyst, and ossification of the ligament are included in the differential diagnosis, and contrast MRI is useful for the definitive diagnosis. When a space-occupying lesion is observed in the spinal canal in the lower thoracic spinal region, it is necessary to examine it using contrast MRI in consideration of thoracic disc herniation.

\section{Consent}

The patient has given his informed consent for the case report to be published.

\section{References}

[1] Logue, V. (1952) Thoracic Intervertebral Disc Prolapsed with Spinal Cord Compression. Journal of Neurology, Neurosurgery \& Psychiatry, 15, 227-241. http://dx.doi.org/10.1136/jnnp.15.4.227

[2] Love, J.G. and Schorn, V.G. (1965) Thoracic-Disk Protrusions. JAMA, 191, 627-631. http://dx.doi.org/10.1001/jama.1965.03080080017004

[3] Arce, C.A. and Dohrmann, G.J. (1985) Herniated Thoracic Disks. Neurologic Clinics, 3, 383-392.

[4] Fujii, T., Seto, A. and Yamasita, J. (2001) A Case Report of Dorsally Sequestrated Thoracic Disc Herniation. Spinal Surgery, 15, 59-63. (In Japanese)

[5] Hayashi, Y., Ohta, H., Shibayama, M., Suzuki, H. and Takahashi, M. (2002) A Case Report of Thoracic Disc Herniation Sequestrated to the Dorsal Epidural Space. The Journal of the Tohkai Spinal Surgery, 16, 19-22. 
[6] Karimoto, M., Senzoku, F., Ueo, T., Miki, T., Kotani, H., Ota, S., et al. (1999) Dorsal Extrusion of Thoracic Disc: Case Report. Annual Bulletin of Kosei-Nenkin Hospitals, 26, 25-30. (In Japanese)

[7] Kitano, S., Kato, Y., Hirano, N., Sekido, H. and Tsuji, H. (1985) Thoracic Intervertebral Disc Extrusion with Acute Flaccid Paraplegia. Rinsho Seikei Geka, 20, 179-185. (In Japanese)

[8] Miyakoshi, Y., Hongo, M., Kasukawa, Y., Ishikawa, Y. and Shimada, Y. (2013) Posteriorly Migrated Thoracic Disc Herniation: A Case Report. Journal of Medical Case Reports, 7, 41. http://dx.doi.org/10.1186/1752-1947-7-41

[9] Morita, K., Kira, H., Makino, Y., Hurukawa, K., Iwasaki, K., Onishi, H., et al. (1998) A Case Report of Thoracic Disc Herniation Sequestrated to the Dorsal Epidural Space. Seikeigeka and Saigaigeka, 47, 21-24. (In Japanese)

[10] Morizane, A., Hanakita, J., Suwa, H., Ohshita, N., Gotoh, K. and Matsuoka, T. (1999) Dorsally Sequestrated Thoracic Disc Herniation-Case Report. Neurologia Medico-Chirurgica (Tokyo), 39, 769-772. http://dx.doi.org/10.2176/nmc.39.769

[11] Tanno, I., Takebatashi, Y., Kawaguchi, S., Yokozawa, H., Yamasita, T. and Yokogushi, K. (1997) Thoracic Sequestrated Disc Herniateon, Report of Two Cases. Seikeisaigaigeka, 40, 1373-1377. (In Japanese)

[12] Ymanashi, H., Takahashi, Y., Ogawa, J. and Sinozaki, Y. (2015) A Case of Thoracic Disc Herniateon Dorsally Sequestrated to Extradural Space. Higashinihon Seikei Saigaigeka Gakkai Zasshi, 27, 109-113. (In Japanese)

[13] Yukawa, Y., Watanabe, K., Urata, S., Yazaki, S., Oowaki, Y., Yamada, T., et al. (1994) A Case Report of Sequestrated Disc Herniation in Thoracic Spine. Seikeigeka, 45, 603-606. (In Japanese)

[14] Watanabe, T., Ito, Y. and Oda, T. (2011) Thoracic Disc Herniation Sequestrated to the Dorsal Epidural Space: A Case Report. Chubu Seikei Saigaigeka Gakkai Zasshi, 54, 1229-1230. (In Japanese)

[15] Bose, B. (2003) Thoracic Extruded Disc Mimicking Spinal Cord Tumor. The Spine Journal, 3, 82-86. http://dx.doi.org/10.1016/S1529-9430(02)00206-1

[16] Kim, I.S., Lee, S.W., Son, B.C. and Sung, J.H. (2008) Posterior Epidural Migration of Thoracic Disc Fragment. Journal of Korean Neurosurgical Society, 43, 239-241.

[17] Partheni, M., Fratzoglou, M., Kalogeropoulou, C.H., Zabakis, P., Panagiotopoulos, V. and Konstantinou, D. (2005) Dorsal Extradural Thoracic Disc Fragment: A Diagnostic Challenge. Journal of Spinal Disorders \& Techniques, 18, 544-546.

[18] Song, K.J., Kim, K.B. and Lee, K.B. (2012) Sequestrated Thoracic Disc Herniation Mimicking a Tumoral Lesion in the Spinal Canal-A Case Report. Clinical Imaging, 36, 416-419.

[19] Yano, S., Hida, K., Seki, T., Iwasaki, Y., Akino, M. and Saitou, H. (2004) A Case of Thoracic Disc Herniation with Sudden Onset Paraplegia on Toilet Straining: Case Report. No Shinkei Geka, 31, 1297-1301.

[20] White, A.A. and Panjabi, M.M. (1978) The Basic Kinematics of Human Spine. Spine, 3, 12-20. http://dx.doi.org/10.1097/00007632-197803000-00003 